\title{
LEFT VENTRICULAR FILLING PRESSURE GRADIENT IN MITRAL INCOMPETENCE
}

\author{
BY \\ P. G. F. NIXON AND G. H. WOOLER \\ From the Departments of Thoracic Surgery and Medicine, the General Infirmary, Leeds \\ Received August 17, 1962
}

During the period of ventricular filling the mean pressure gradient across the normal mitral valve measures between 0 and $1 \mathrm{~mm}$. $\mathrm{Hg}$. In mitral stenosis the gradient is pathologically increased by an amount that depends upon the severity of the constriction and upon the nature and quantity of the blood flow through the orifice (Braunwald et al., 1955). While this much is generally accepted, there is little agreement about the findings in mitral incompetence. Most reports suggest that an abnormally large left ventricular filling pressure gradient is a sign of obstruction that should not occur in "pure" mitral incompetence (Braunwald et al., 1955; Moscovitz and Wilder, 1957; Dickens et al., 1957; Marshall and Wood, 1958; Björk and Malmström, 1959; Lancet, 1959; Luisada and Liu, 1959). In mitral incompetence some have recorded a pressure gradient that was "rapidly disappearing", found "only in early diastole", or "small" (Fox et al., 1956; Musser, Bougas, and Goldberg, 1956; Hamer and Dow, 1961). Others have said that the mitral diastolic pressure gradient of incompetence is indistinguishable from that of stenosis (Marshall, Connolly, and Wood, 1957; Dexter et al., 1957). Davila recognized the occasional occurrence of a large left ventricular filling pressure gradient in severe mitral incompetence, and suggested that in this condition a mitral orifice of normal size might be too small to carry without hindrance the greatly excessive diastolic blood flow (Davila, 1958; Davila et al., 1958).

In this clinic the left atrial and ventricular pressure pulses were measured simultaneously at cardiac catheterization in five patients who were subsequently treated surgically for mitral incompetence. Abnormally large left ventricular filling pressure gradients were found. In some patients the atrio-ventricular ring was dilated, the mitral orifice was larger than normal, the cusps did not adhere to each other, and no element of organic obstruction was present.

The purpose of this communication is to describe the left ventricular filling pressure gradients that were recorded, and to consider the clinical implications of their presence.

\section{SubJECTS AND METHODS}

The left atrial and the left ventricular pressures were measured simultaneously during cardiac catheterization in five women shortly before their surgical treatment. They were considered to be disabled by atrial fibrillation and chronic rheumatic mitral valvular disease, and to be free from congestive heart failure and from aortic valvular, hypertensive, and ischæmic heart disease. Pulmonary hypertension was present. Mitral pansystolic murmurs were audible, and the diagnosis of pure or predominant mitral incompetence was made from the presence of all of the following findings: clinical and radiological evidence of left ventricular enlargement; a left ventricular apical impulse displacement curve (Schneider and Klunhaar, 1961) showing prominent inward movement at the time of the third heart sound, and evidence of stasis in diastole; a third heart sound and diastolic murmur characteristic of incompetence (Nixon and Wooler, 1960; Nixon, 1961a and b); a left atrial stasis wave revealing raised left ventricular end-diastolic pressure and disappearance of the atrio-ventricular pressure gradient (Nixon and Wooler, 1961); and gross distortion of the blue 
dye (Nixon and Snow, 1962) or ascorbic acid (Nixon et al., 1963) dilution curve obtained by injecting the indicator into the left atrium.

The Investigation. Knowing that slight changes in the condition of the patient with mitral incompetence can alter greatly the left heart pressure pulses, an earnest attempt was made, by using sedatives and by training the patient and the laboratory staff, to obtain the measurements at cardiac catheterization during a basal, steady state. Transeptal catheterization of the left atrium was carried out in the manner described previously (Nixon, 1960), and the left ventricle was entered by apical percutaneous puncture (Brock, Milstein, and Ross, 1956). The left atrial pressure was re-

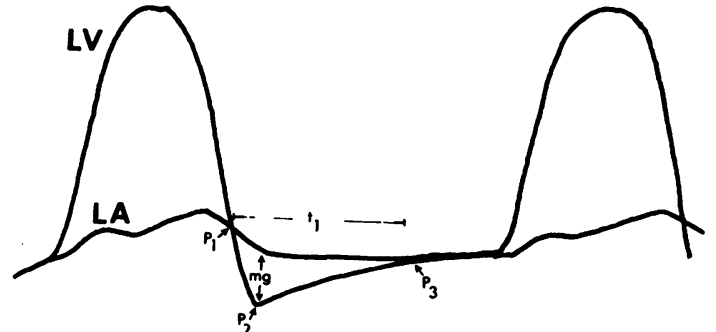

FIG. 1.-Mitral incompetence. The measurements described in the text are indicated on this tracing of simultaneously recorded left atrial (LA) and left ventricular (LV) pressure pulses. corded through a $90 \mathrm{~cm}$. P.E. 50 catheter, and the left ventricular pressure through an $8 \mathrm{~cm}$. 21 gauge needle and $50 \mathrm{~cm}$. of $3 \mathrm{~mm}$. I.D. inelastic nylon tubing. Two equisensitive Statham P23G transducers were used. The pressures were recorded during expiratory pauses with a camera at a paper speed of $80 \mathrm{~mm}$./sec. The zero reference point was the sternal angle, and the calibration was in $\mathrm{mm}$. Hg. The zero-setting and sensitivity of each system were checked before and after the recording. The mitral and pulmonary area phonocardiograms and the lead II electrocardiogram were recorded simultaneously with the pressure pulses. The site of the percutaneous puncture did not allow the mitral area microphone to be placed in the most favourable position for recording the third heart sound and diastolic murmur.

Measurements. An abnormally large left ventricular filling pressure gradient occurred in every cardiac cycle in every patient. In the shorter cardiac cycles the gradient persisted until systole raised the ventricular pressure above the atrial, but in the longer cycles the gradient was abolished by the equalization of the ventricular and atrial pressures in diastole. Measurements were taken from those cycles in which diastole lasted long enough for the ventricular and atrial pressures to equalize, and were averaged for at least 10 cycles. The measurements were as follows.

(1) The pressure at the point at which the declining left ventricular pressure met and fell below the left atrial pressure just before the mitral opening snap $\left(P_{1}\right.$, Fig. 1).

(2) The time interval between this point and the subsequent equalization of the left atrial and ventricular pressures $\left(t_{1}\right.$, Fig. 1).

(3) The maximum difference in pressure between the left atrium and the left ventricle in diastole ( $\mathrm{m} \mathrm{g}$, Fig. 1).

(4) The lowest point of the left ventricular pressure in diastole $\left(P_{2}\right.$, Fig. 1).

(5) The pressure at the point of equalization of the left atrial and ventricular pressures in diastole $\left(P_{3}\right.$, Fig. 1).

As a safeguard against failure to recognize artefactual slurring of the pressure pulses, the time interval was measured between $\mathbf{P}_{1}$ and the opening snap.

Operation. At open-heart operation the valve was examined and repaired (Wooler et al., 1962). The long diameter of the mitral orifice was estimated by inspection and palpation, and the presence or absence of organic obstruction was determined.

\section{RESULTS}

In three patients, the mitral incompetence was caused by dilatation of the atrio-ventricular ring; the long diameter of the mitral orifice measured $5.0 \mathrm{~cm}$. or more; there was no fusion of the cusps; and no evidence of organic obstruction to the flow of blood from the atrium to the ventricle. In two patients, the long diameter of the mitral orifice measured between 3 and $4 \mathrm{~cm}$., and anteriorly and posteriorly the cusps were fused.

In the three patients free from cusp fusion, the declining left ventricular pressure curves crossed the left atrial pressure curves at 31,16 , and $36 \mathrm{~mm}$. $\mathrm{Hg}$, reached nadirs of 6,3 , and $2 \mathrm{~mm} . \mathrm{Hg}$, and 


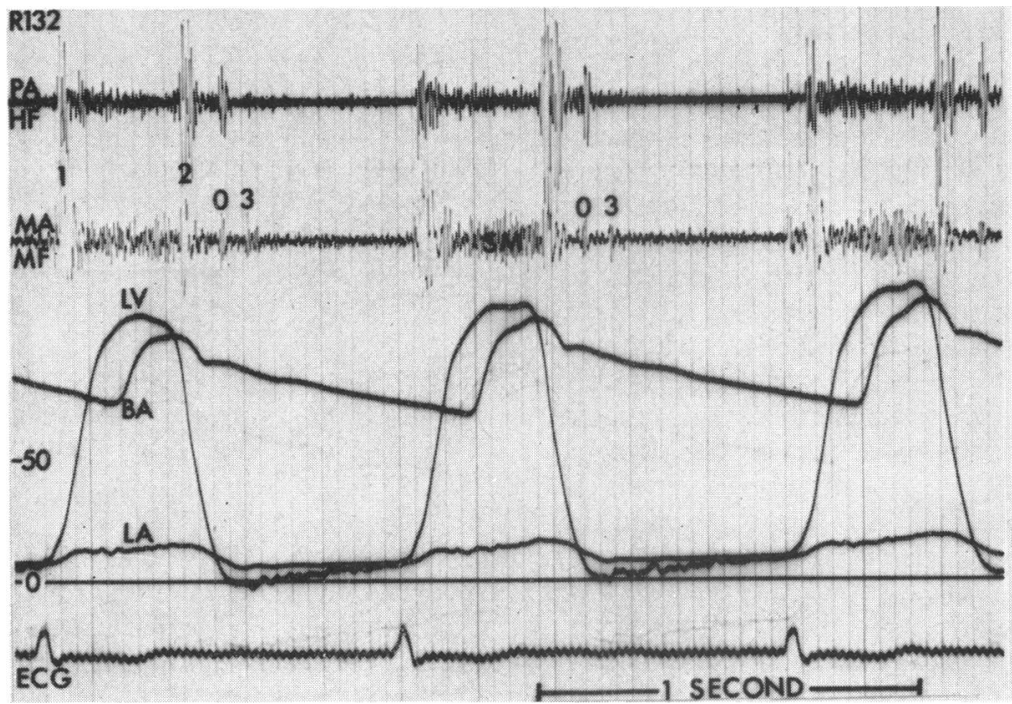

FIG. 2.-Pure mitral incompetence. Simultaneously recorded pulmonary area high frequency (PA/HF) and mitral area medium frequency (MA/MF) phonocardiograms, the brachial arterial (BA), left ventricular (LV), and left atrial (LA) pressure pulses, and the lead II electrocardiogram (E.C.G.). Scale is in $\mathrm{mm}$. Hg. Symbols used in this or the following illustrations are as follows. 1, $2=$ first and second heart sound; $3=$ third heart sound; $\mathbf{O}=$ mitral opening snap; $\mathbf{S M}=$ mitral pansystolic murmur; $\mathrm{DM}=$ mitral diastolic murmur; and $\mathrm{A}=$ left atrial annular ascent point.

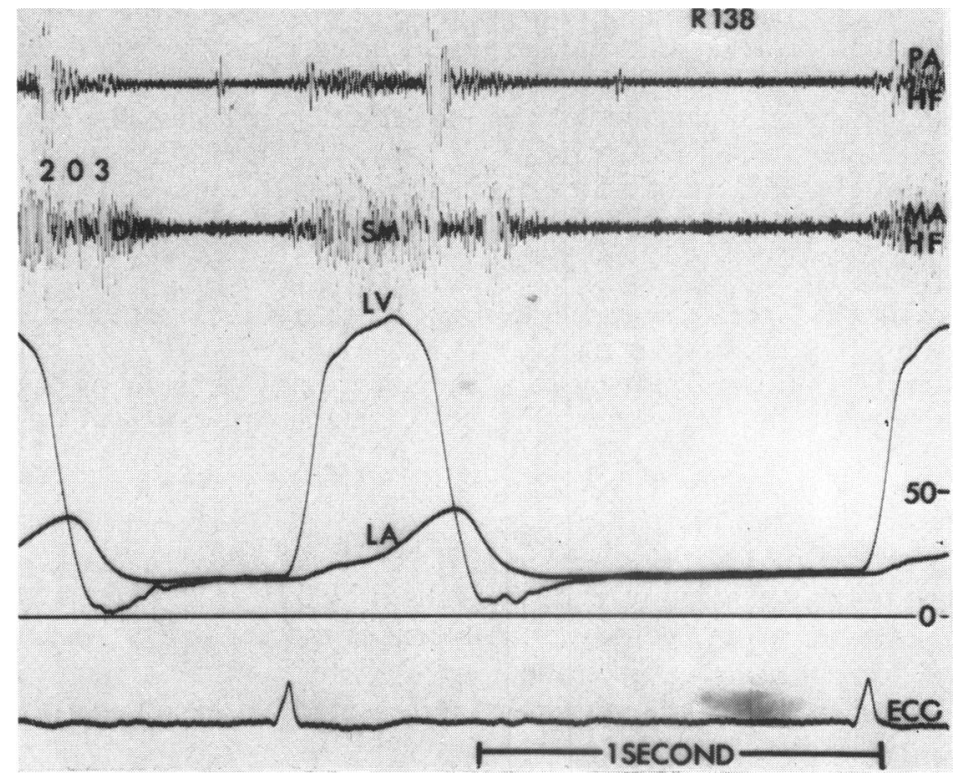

FIG. 3.-Pure mitral incompetence. Symbols as in Fig. 2. 
climbed again to equalize with the left atrial pressures at 12,10 , and $14 \mathrm{~mm}$. $\mathrm{Hg}$, respectively. The separation of the two pressure curves lasted $0.32,0.47$, and 0.35 seconds $(t$,) and the pressure gradients $(\mathrm{m} \mathrm{g})$ at the time of maximum separation were 15,10 , and $25 \mathrm{~mm}$. $\mathrm{Hg}$. The records are illustrated in Fig. 2 and 3.

In the two patients with a degree of cusp fusion, the left ventricular pressures crossed the left atrial at 39 and $20 \mathrm{~mm} . \mathrm{Hg}$, reached nadirs of 3 and $2 \mathrm{~mm}$. $\mathrm{Hg}$, and equalized again with the left atrial pressures at 21 and $8 \mathrm{~mm}$. $\mathrm{Hg}$. The durations of the gradients were 0.51 and $0.58 \mathrm{sec}$. and the maximum gradients measured 20 and $11 \mathrm{~mm}$. $\mathrm{Hg}$ (Fig. 4).

A mitral diastolic murmur and an opening snap were recorded in every patient. The murmur and the left ventricular filling pressure gradient tended to resemble each other in shape and duration.

The cross-over point of the left ventricular and atrial pressures $\left(P_{1}\right)$ occurred 16 to 36 milliseconds before the phonocardiograph recorded the onset of the mitral opening snap vibrations.

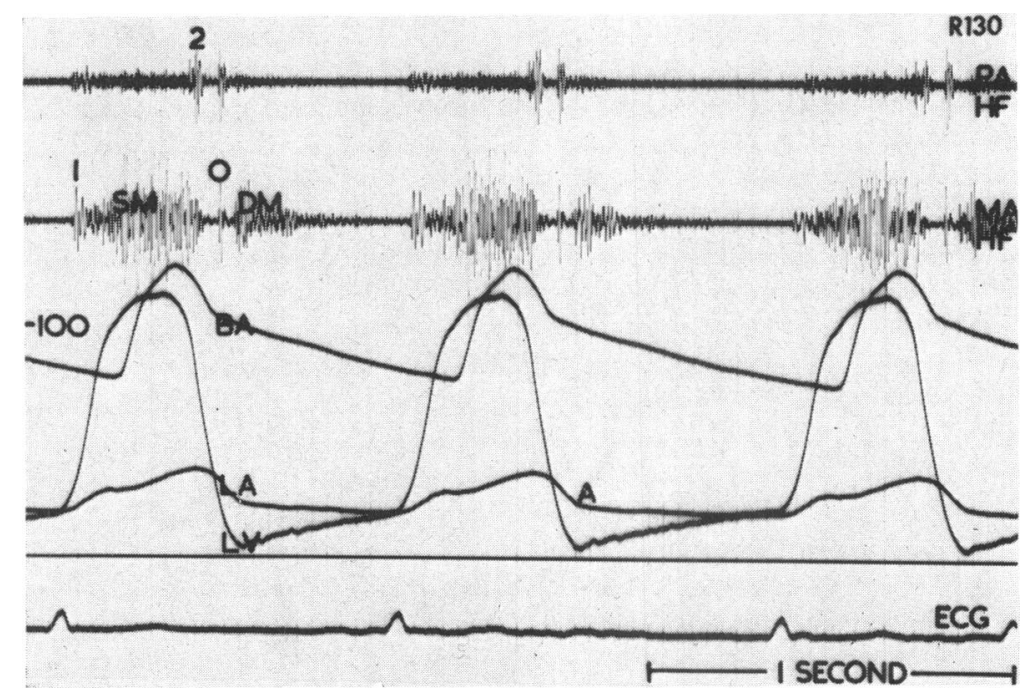

FIG. 4.-Mitral incompetence with a degree of fusion of the cusps. Symbols as in Fig. 2.

\section{Discussion}

This study has shown that an abnormally large left ventricular filling pressure gradient and a diastolic murmur can occur in pure mitral incompetence as well as in cases where there is an element of valvular stenosis. Three factors may be responsible for this phenomenon. The mitral orifice may be small in relation to the excessive atrio-ventricular blood flow of mitral incompetence, even though it is larger than normal and free from cusp fusion. Turbulence in the blood flowing from the atrium to the ventricle may be partly or wholly responsible for the creation of a pressure gradient and murmur. In mitral incompetence the left ventricle carries an abnormally large volume of blood, and, in this situation, vigorous ascent of the mitral annulus fibrosus at the time of the third heart sound might tauten the valve sufficiently to reduce the lumen by drawing the cusps towards each other (Nixon, 1961a).

The most important diagnostic feature of the left ventricular filling pressure gradient of mitral incompetence is the fact that it can be demonstrated to disappear in diastole during cardiac catheterization, if the heart rate is slow enough and if the patient is in a basal or nearly basal condition. 
It is not necessary to enter the left ventricle to learn whether the gradient disappears, because the fact of equalization of the atrial and ventricular pressures can be recognized from the left atrial stasis wave (Nixon and Wooler, 1961) and, probably, from the diastolic murmur. Disappearance of the gradient is not likely to be encountered at cardiac catheterization unless the long diameter of the mitral orifice measures about $2.0 \mathrm{~cm}$. or more (Nixon and Wooler, 1961).

The rapidity with which the gradient disappears seems to be directly proportional to the size of the mitral orifice.

If tachycardia occurs during cardiac catheterization, or if a rise in peripheral resistance greatly increases the mitral regurgitation, the pressure gradient and the diastolic murmur may persist throughout every diastole, and it may be difficult to decide whether the predominant mitral lesion is obstructive or incompetent. In this situation it is helpful to examine the diastolic murmur and the left ventricular pressure curve. Where incompetence is predominant the mitral diastolic murmur

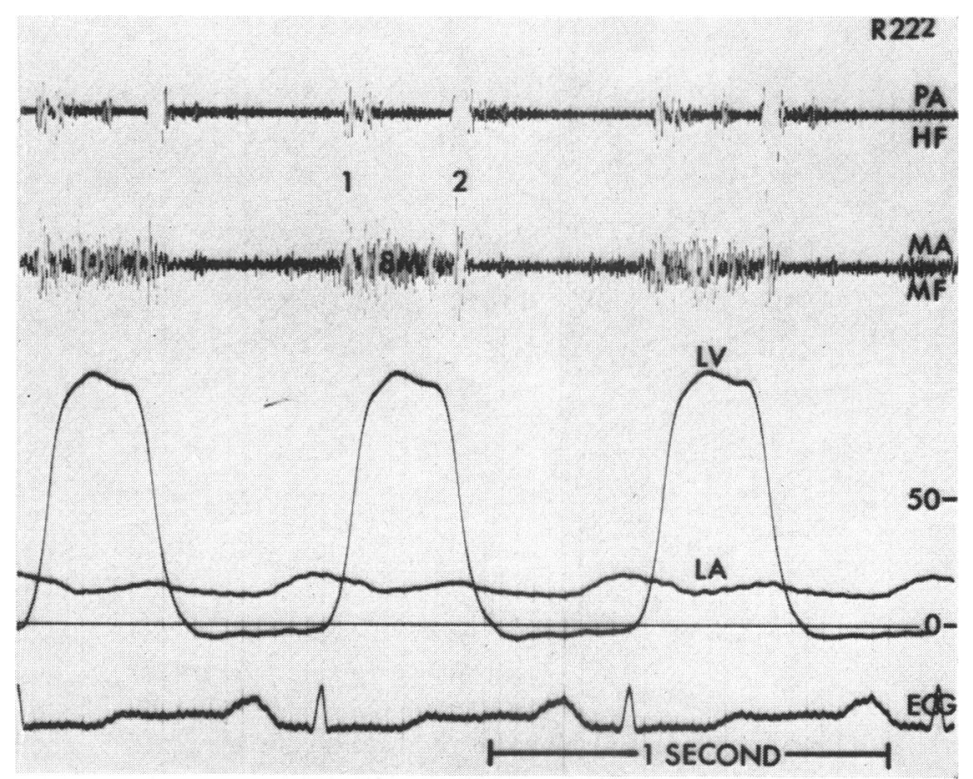

FIG. 5.-Mitral stenosis with regurgitation. Symbols as in Fig. 2

usually begins loudly at the time of the third heart sound and annular ascent point, and it svibrations tend to diminish rapidly in size. Where obstruction is predominant the murmur begins close to the opening snap and does not alter much in loudness as it rumbles through diastole (Nixon, $1961 \mathrm{a}, \mathrm{b})$. The diastolic portion of the left ventricular pressure curve usually climbs slowly in predominant obstruction and remains below the level of the sternal angle (Fig. 5). In severe mitral incompetence it usually climbs rapidly to an abnormal height.

The presence of an abnormally large mitral diastolic pressure gradient in mitral incompetence sometimes tempts the physician to recommend valvotomy in the hope that the patient will benefit from the relief of a degree of obstruction. This advice should be weighed carefully because cardiotomy may reveal no sign of obstruction. If the cusps are fused anteriorly and posteriorly, commissurotomy may be followed by steadily increasing disability from incompetence because the fusion of the cusps prevented dilatation of the atrio-ventricular ring and protected the heart from the vicious cycle of events described by Burchell and Edwards (1953). 
In mitral incompetence it appears that a degree of fusion of the mitral leaflets cannot be diagnosed or excluded by reference to the left ventricular filling pressure gradient, and so it may not be possible to distinguish "pure" from "predominant" mitral incompetence. Earlier in this paper it was stated that the diagnosis of pure or predominant mitral incompetence was made from a combination of certain signs in disabled patients presenting with pulmonary hypertension, atrial fibrillation, and a mitral pansystolic murmur. The signs comprised left ventricular enlargement, a prominent inward movement of the left ventricular apex at the time of the third heart sound, a third heart sound and characteristic diastolic murmur, a left atrial stasis wave revealing elevation of the left ventricular end-diastolic pressure, and gross distortion of the dilution curve. Each of these signs except the last probably owes its presence to an excessive left ventricular blood volume, and we have not encountered the combination in cases where fusion of the cusps or chordæ tendinæ has reduced the mitral lumen to about $1.5 \mathrm{~cm}$. or less, and caused obstruction to left ventricular filling to be the predominant hæmodynamic disorder. The signs that make up the combination may be more prominent in "pure" mitral incompetence than in "predominant" mitral incompetence, where there is an element of cusp fusion, but they are not different in kind. We believe that there is little to be gained by attempting to distinguish between "pure" and "predominant" mitral incompetence before operation. It does not seem important to diagnose an element of cusp fusion when the patient has excessive left ventricular filling and the other physiological disturbances of mitral incompetence.

Cases occupying the borderland between obstruction and incompetence appear to be uncommon. Probably they may be recognized by the exceptional length of diastole that is required for the disappearance of the mitral diastolic pressure gradient and murmur, and for the appearance of a left atrial stasis wave. The left ventricle is but slightly enlarged, the apex of the left ventricle moves inwards only a little at the time of the third heart sound, a third sound occurs in a small minority of cardiac cycles, the diastolic murmur appears and waxes before the time of the third sound, and an opening snap is rarely present. The few cases that we have encountered have not been amenable to treatment either by valvotomy or repair; the whole valve mechanism has been ankylosed, and the orifice has measured about 1.5 to $2 \mathrm{~cm}$.

\section{SUMMARY}

Abnormally large left ventricular filling pressure gradients were recorded at cardiac catheterization in pure mitral incompetence, and in predominant mitral incompetence where there was a degree of fusion of the mitral valve cusps. The pressure gradients are described and illustrated, and their clinical implications are discussed.

The left ventricular filling pressure gradient of severe mitral incompetence differs from the gradient of severe obstruction in that it can be demonstrated to disappear if the heart rate is slow enough, and if the patient is in a basal or nearly basal condition.

The authors are grateful to Mr. R. Addyman, Mr. H. Ketteringham, and Mrs. J. Blake for assistance, and thank the Board of Governors of the United Leeds Hospitals, the Nuffield Foundation, the Medical Research Council, the Endowment Fund of the Infirmary, and private benefactors for providing equipment.

\section{REFERENCES}

Björk, V. O., and Malmström, G. (1959). The diastolic pressure gradient between the left atrium and the left ventricle in cases of mitral stenosis. Amer. Heart J., 58, 486.

Braunwald, E., Moscovitz, H. L., Amram, S. S., Lasser R. P., Sapin, S. O., Himmelstein, A., Ravitch, M. M., and Gordon, A. J. (1955). The hemodynamics of the left side of the heart as studied by simultaneous left atrial, left ventricular, and aortic pressures; particular reference to mitral stenosis. Circulation, $12,69$.

Brock, R., Milstein, B. B., and Ross, D. N. (1956). Percutaneous left ventricular puncture in the assessment of aortic stenosis. Thorax, 11, 163.

Burchell, H. B., and Edwards, J. E. (1953). Rheumatic mitral insufficiency. Circulation, 7, 747. 
Davila, J. C. (1958). Hemodynamics of mitral insufficiency. Observations from clinical and experimental surgery. Amer. J. Cardiol., 2, 135.

_-, Glover, R. P., Voci, G., Jumbala, P., Trout, R. G., and Fritz, A. J. (1958). The clinical and physiologic criteria for surgical correction of mitral insufficiency. J. thorac. Surg., 35, 206.

Dexter, L., Novack, P., Schlant, R. C., Phinney, A. O., and Haynes, F. W. (1957). Mitral insufficiency. Trans. Ass. Amer. Phycns, 70, 262.

Dickens, J., Raber, G., Woldow, A., Lorange, G. C., and Goldberg, H. (1957). A study of mitral stenosis by combined catheterization of the left and right sides of the heart. New Engl.J. Med., 256, 1017.

Fox, I. J., Wakai, C. S., Connolly, D. C., and Wood, E. H. (1956). Left atrial and ventricular pressure pulses in mitral valvular disease. Proc. Mayo Clin., 31, 126.

Hamer, N. A. J., and Dow, J. W. (1961). Selection of techniques for the measurement of left heart pressures. Brit. Heart J., 23, 317

Lancet (1959). Annotation. Mitral incompetence. 1, 134.

Luisada, A. A., and Liu, C. K. (1959). Left heart catheterisation in rheumatic heart disease. In Cardiology, an Encyclopedia of the Cardiovascular System, Vol. 3, ed. A. A. Luisada. McGraw-Hill New York.

Marshall, H. W., Connolly, D. C., and Wood, E. H. (1957). Differentiation of mitral stenosis and mitral regurgitation by means of left atrial pulse contours. Circulation, 16, 913.

- and Wood, E. H. (1958). Hemodynamic considerations in mitral regurgitation. Proc. Mayo Clin., $33,517$.

Moscovitz, H. L., and Wilder, R. J. (1957). The pressure events of the cardiac cycle in the dog: mitral valve lesions. Amer. Heart J., 53, 741.

Musser, B. G., Bougas, J., and Goldberg, H. (1956). Left heart catheterization. II. With particular reference to mitral and valvular disease. Amer. Heart J., 52, 567.

Nixon, P. G. F. (1960). The transeptal approach to the left atrium in mitral regurgitation. Thorax, 15, 225.

- (1961a). The third heart sound in mitral regurgitation. Brit. Heart J., 23, 677.

(1961b). The low-flow and the high-flow mitral diastolic murmurs. Brit. Heart J., $23,462$.

- Hay, G. A., Hepburn, F., Snow, H. M., and Addyman, R. (1963). An amperometric technique for recording ascorbate dilution curves and blood flow pulses. Brit. Heart J., 25, 173.

- , and Snow, H. M. (1962). Indicator dilution curves in mitral valvular disease. Brit. Heart J., $24,637$.

—, and Wooler, G. H. (1960). Clinical assessment of mitral orifice in patients with regurgitation. Brit. med. J., 2, 1122.

$\overline{\mathrm{C}}, \frac{2,1122 .}{(1961) .}$ Rapid left ventricular filling and stasis in mitral regurgitation. Brit. Heart J., $23,161$.

Schneider, H., and Klunhaar, E. W. J. M. (1961). Precordial low-frequency displacements of the thoracic wall. Method of recording and registration. Amer. Heart J., 61, 670.

Wooler, G. H., Nixon, P. G. F., Grimshaw, V. A., and Watson, D. A. (1962). Experiences with the repair of the mitral valve in mitral incompetence. Thorax, 17, 49. 